DOI: 10.20472/IAC.2018.042.003

ERIC BATES

Dublin Institute of Technology, Ireland

\title{
THE EFFECTS OF THE LEAVING CERTIFICATE POINTS ON PROGRESSION IN HIGHER EDUCATION IN IRELAND.
}

\begin{abstract}
:
In Ireland entry into higher education undergraduate courses is processed by the Central Applications Office (CAO) and can be applied through many routes. The most common application is based upon the Leaving Certificate Examination results. Those applying through such a facility are referred to as standard entrants. The Leaving Certificate Examination is a terminal exam which occurs at the end of the Senior Cycle in post-primary schools in the Republic of Ireland. Students may take examinations in a number of subjects with results being awarded in the form of grades. These grades are then assigned a points value. Candidates also have the option of sitting a Higher or Lower paper with the Higher paper being the more difficult choice. As a result the grades achieved in a Higher paper are worth more points than those from a Lower paper. Those students with the highest points are offered places on the most sought after programmes. There are also students classified as 'non standard entrants' who access higher education by other means than the Leaving Certificate examination. Having achieved their place in higher education though the various entry routes the statistics show that the dropout rate among first year students is significant. This research set out to examine whether there are any differences in retention rates among a number of different categories of student within an Institute of Technology in Dublin. Those categories are male, female entrants and standard and non-standard entrants. Leaving Certificate points achievement was also be used as a variable in analysing retention. A dataset was utilised in SPSS to examine five hypothesis.
\end{abstract}

\section{Keywords:}

Retention; higher education; first year experience;

JEL Classification: 129 